DOI: https://doi.org/10.32870/

eees.v21i60.292

Joanna Jablonska-Bayro•

\title{
Ante las seguridades evanescentes. Riesgo y subjetividades en la ciudad de Guadalajara
}

Escondida en lo más profundo de las dinámicas éticas, políticas y culturales de la modernidad se encuentra la idea de un sujeto autosuficiente, hermético, acorazado, separado del exterior, que defiende su totalidad negando su propia fragilidad y dependencia de la comunidad. Varios autores contemporáneos (Esposito,

Este artículo presenta los hallazgos de una investigación etnográfica sobre las formas en que los riesgos propios de la modernidad configuran subjetividades en distintas posiciones sociales de la ciudad de Guadalajara.

El análisis se enfoca en la relación de los sujetos con las instituciones Estado, trabajo y familia, en los significados y en las prácticas que surgen en torno a la cotidianidad urbana marcada por la expansión de lo siniestro, $y$ en las concepciones de lo común en el contexto de inseguridad. El riesgo se revela como un dispositivo de control con un fuerte poder individualizador y fragmentador, capaz de debilitar la agencia social y de exacerbar la actual precariedad de lo común.

Palabras clave: subjetividades, riesgo, inseguridad, individualización, instituciones, ciudad, lo común.

- Profesora adjunta en el Departamento de Estudios Socioculturales del Instituto Tecnológico de Estudios Superiores de Occidente mariajablonska@iteso.mx
2005; Cavarero, 2009; Butler, 2006) destacan la importancia de cuestionar y de desestabilizar esta concepción del sujeto, revelando sus paradojas, sus peligros, su carácter ilusorio. El artículo que aquí presento es el resultado de una serie de hallazgos que invitan a cuestionar la concepción moderna del sujeto sumergido en el reino de lo individual. Los resultados a los que llegó mi trabajo de recepción doctoral, y de los cuales aquí presento una parte, constituyen un peldaño más para seguir reflexionando sobre las posibilidades de concebir el sujeto y su relación con lo común de maneras diferentes, así como las posibilidades que este tiene de abrirse hacia socializaciones menos individualistas.

Las inquietudes que me motivaron giraron en torno al papel que 
tienen el riesgo y las incertidumbres propios de la modernidad como configuradores de subjetividades; es decir, mi preocupación fue entender en qué medida los peligros e inseguridades contemporáneos influyen en las actitudes de los sujetos y contribuyen a formar sus distintas subjetividades. Para entender lo anterior, observé subjetividades inmersas en un tiempo-espacio específico (la ciudad de Guadalajara ${ }^{1}$ en el sexenio calderonista ${ }^{2}$, desiguales y complejas, y configuradas desde las diferencias estructurales y culturales entre los individuos.

La teoría cuyos postulados me permitieron interpretar los hallazgos fue la de la sociedad de riesgo, de Ulrich Beck, donde el autor interpreta la contemporaneidad como una época de simultánea exacerbación y crisis de las dinámicas modernas; proceso que desemboca en la profundización del riesgo definido como "el presente de catástrofes futuras" (Beck, 2008: 27). Su concepción de riesgo es una categoría pertinente para pensar lo contemporáneo como parte de la episteme (concebida a manera de Michel Foucault) o como un ingrediente de lo que Raymond Williams (2000) propone llamar estructuras de sentir. ${ }^{3}$ Observar lo social desde la perspectiva del riesgo ofrece la oportunidad de encontrar en lo cotidiano y en lo aparentemente individual huellas de lógicas y dinámicas definitorias de lo contemporáneo.

\footnotetext{
I. Una urbe en constante transformación y expansión, atravesada por divisiones y desigualdades antiguas y recientes, marcada por el riesgo y la inseguridad en sus diversos escenarios.

2. Enrique Calderón fue presidente de México de 2006 a 2012. Su sexenio caracterizó por la profundización de la crisis económica y por el dramático aumento de violencia e inseguridad relacionado con la llamada "guerra contra el narcotráfico".

3. Las estructuras de sentir son "[...] una experiencia social que todavía se halla en proceso, que a menudo no es reconocida verdaderamente como social, sino como privada, idiosincrática e incluso aislante, pero que en el análisis [...] tiene sus características emergentes, conectoras y dominantes" (Raymond Williams, 2000: 155).
} 
Así, enfoqué la investigación en la cotidianidad de sujetos históricamente situados para observar cómo dotan de sentido los riesgos a los que se ven expuestos en el día a día y cuáles son las prácticas y actitudes que adoptan en torno a esos peligros. Realicé un estudio cualitativo de carácter etnográfico en la zona metropolitana de Guadalajara. El corpus de la investigación se conformó por $i$ ) doce entrevistas con sujetos de perfiles diferenciados, ${ }^{4} i$ i) siete entrevistas con sujetos vinculados con la 'gestión' de riesgo (entre otros, un militar, un sacerdote, una asesora de seguros y un médico), iii) textos mediáticos y $i v$ ) mis propias observaciones etnográficas recogidas en distintos escenarios locales. De los anteriores, presentaré aquí únicamente las narrativas recogidas en las primeras doce entrevistas, las cuales condujeron a los descubrimientos que aquí he organizado en tres ejes analíticos sobre cuestiones que cobraron centralidad durante el análisis de las narrativas: i) la relación de los sujetos con las instituciones Estado, trabajo y familia; ii) los significados y las prácticas que surgen en torno a la cotidianidad urbana marcada por la inseguridad creciente; y iii) las concepciones de lo común en el contexto del riesgo.

Las cuestiones que abordaré en los apartados siguientes se muestran al observador como fenómenos especialmente relevantes si se les enmarca en el todo interrelacionado del que se desprenden y del que son evidencia: el creciente debilitamiento de las instituciones como fuentes de seguridad y la consiguiente responsabilización del sujeto, la vulnerabilidad del sujeto-cuerpo dentro de la cotidianidad urbana (cada vez más amenazante), y la difícil relación del sujeto con lo común, eso que es añorado como fuente de protección pero que es difícilmente asumible en sus contradicciones y ambivalencias. Observadas estas cuestiones como partes de

4. Para la elección de los sujetos se consideraron: el género, la edad, el estrato socioeconómico, la escolaridad, la inclinación política, la adscripción religiosa, así como el lugar y el tiempo de residencia en la ciudad. 
Joanna Jablonska-Bayro

un todo abarcador permiten interpretar el riesgo como un dispositivo de control con un fuerte poder individualizador y fragmentador, capaz de debilitar la agencia social y de exacerbar la actual precariedad de lo común.

\section{El Estado: un protector ambiguo}

Uno de los temas que destacan dentro del corpus recolectado es la relación de los sujetos con la institución del Estado. El paulatino desmantelamiento del Estado de bienestar y la acelerada propagación de políticas securitarias (Bauman, 2005; Vara, 2006) encuentran un claro reflejo en las narrativas. El Estado como proveedor de bienestar es criticado severamente por sus supuestos beneficiarios. Desde la perspectiva de varios sujetos, especialmente los más vulnerables, el Estado de bienestar se revela insuficiente y a veces inexistente, sin duda, marcado por el cinismo y la corrupción de los gobernantes. También las exacerbadas políticas securitarias, destinadas presuntamente a garantizar la seguridad ciudadana (mencionadas en las entrevistas con más frecuencia que las políticas sociales), encuentran escasa aprobación y, en algunos casos, son interpretadas como equivocadas o aparentes, injustas y marcadas por la parcialidad. El Estado es narrado a menudo como una institución lejana, opaca, corrupta y cínica, que no solamente falla a menudo en el cumplimiento de su función de garante de seguridad, sino que es en sí misma una amenaza.

Dicha percepción encuentra una expresión evidente en lo narrado sobre las encarnaciones más visibles y cotidianas del Estado securitario: los policías. Citlali, habitante de un barrio popular, menciona robos al tren situado en las cercanías de su casa, los cuales convierten su vecindario en un escenario de arrestos aleatorios: 
Ahora se calmó un poco, pero el mes pasado estaba muy fuerte. Así de que "ya robaron el tren y escóndanse", porque la policía va pasando y agarran a quien... agarraban a quien fuera y vámonos. Uno no sabe a qué horas le puede tocar a uno. [...] Y los policías saben quiénes son los que roban, pero ¿qué hacen?, hay que despistar... hay que buscar un chivo expiatorio.

También para Álvaro, quien ha crecido en un barrio marginado en las afueras de la ciudad, la figura del policía es la personificación del peligro:

Si me preguntas de quién tengo más miedo, o sea, un policía o un ratero, le tengo más miedo a un policía. [...] A mí ya me han robado policías durante una revisada. Ya me han robado mi dinero. [...] Ya te están plantando droga, te la plantan, o sea, con la mano en la cintura... Y en el Ministerio Público ¿a quién le van a creer: a un policía o a ti? Claro que le van a creer a un policía.

Los sujetos más desprotegidos en cuanto a su situación socioeconómica y su lugar de residencia parecen reconocer en el policía corrupto un representante del Estado que, aunque en apariencia es protector de los ciudadanos y defensor de la justicia, en realidad se revela arbitrario y capaz de una violencia aleatoria que acrecienta la vulnerabilidad de los más expuestos en vez de aminorarla.

Esta visión reprobatoria, aunque es la más difundida, no es la única. Hay sujetos que muestran, por un lado, una gran indiferencia hacia el Estado 'benefactor' y, por el otro, una cierta aprobación de su lado securitario. Esta postura se vincula frecuentemente con un nivel socioeconómico elevado que permite prescindir de los servicios sociales del Estado, habitar zonas menos vulnerables y estar, por lo tanto, menos expuesto a los abusos de los agentes estatales; se vincula también con inclinaciones políticas de corte conservador. Aunque este discurso no niega la corrupción y los abusos 
de poder, estos son interpretados como una lamentable excepción de la norma y no como una objetivación de un sistema corrupto y violento. "Ya sé que su misión es cuidar a la gente y a veces no todos lo hacen", comenta Gabriela (habitante de un fraccionamiento cerrado en una de las zonas más privilegiadas de la ciudad) y añade que a pesar de todo no desconfía de los policías.

En términos generales, los sujetos parecen compartir la opinión poco favorable del Estado como proveedor de bienestar, aunque muchos no tienen otra opción que depender de sus escasos servicios, mientras que unos pocos pueden permitirse prescindir de ellos buscando alternativas en el mercado. En cuanto al brazo securitario del Estado, las opiniones y percepciones parecen mucho más polarizadas: la diferenciación entre los que se perciben como ciudadanos (relativamente) protegidos y los que se sienten expuestos frente al poder arbitrario resulta difícil de negar.

En resumen, el Estado se desdibuja como proveedor de seguridad social y se revela profundamente ambivalente como garante de la seguridad ciudadana; pierde sus contornos como protector y se convierte frecuentemente en detonador del riesgo. Ante el cinismo del Estado y su desinterés (o incapacidad) por brindar seguridad a sus ciudadanos, el sujeto se ve obligado a gestionar la seguridad por su propia cuenta, procurando aminorar 'artesanalmente' su vulnerabilidad.

\section{El trabajo: competencia e incertidumbre}

Desde la perspectiva de los sujetos, la centralidad y la importancia del trabajo son innegables, pero en la mayoría de las entrevistas predomina al mismo tiempo la visión del mercado de trabajo como un campo de creciente escasez y disminuida calidad en su oferta de empleo; por lo tanto, el terreno de una competencia exacerbada y desigual, en la 
que ganan pocos y muchos quedan condenados a la precariedad. La tensión entre las expectativas depositadas en el trabajo y la creciente precarización del empleo resulta difícil de ignorar.

Existen, por supuesto, matices que permiten diferenciar las posturas de los sujetos ante la tensión mencionada. Así, en algunas entrevistas (especialmente con sujetos que gozan de cierta estabilidad económica y tienden hacia posturas políticas conservadoras) es reconocible la tendencia de legitimar y justificar las dinámicas del mundo laboral, que son presentadas como 'lógicas' y 'naturales'. Por ejemplo, la escasez del trabajo es explicada como una consecuencia entendible del aumento de la población; la necesidad de tener estudios, como una exigencia lógica de cara al aumento de la competitividad.

No faltan sujetos para quienes el trabajo representa sobre todo la oportunidad de ascender socialmente; en especial los que reconocen su situación como una poco privilegiada, sea porque son jóvenes, porque son mujeres, porque no tienen un trabajo permanente, etc.; en cualquiera de los casos, se trata de sujetos que albergan la esperanza de mejorar su situación. Aquí también las estructuras se naturalizan y justifican, al mismo tiempo que, de manera destacada, la responsabilidad cae en los hombros del sujeto. El mundo del trabajo es visto como un mundo de oportunidades, siempre y cuando el sujeto muestre una actitud adecuada: la flexibilidad, la creatividad, la disposición de adaptarse incesantemente y de aprovechar su capital social. La escasez del empleo llega a ser interpretada como una falacia difundida por los que resultan indispuestos (o incapaces) a 'adecuarse' a las reglas del juego: " "la gente de repente dice

5. En este contexto resulta pertinente mencionar la corriente de autoayuda como oferta de sentido a la que se adhieren algunos de los entrevistados. En cierto sentido, sus lógicas pueden ser consideradas paradigmáticas en cuanto a la condición del sujeto contemporáneo frente al riesgo: la idea de autosuperación se 
que no hay trabajo, que no hay oportunidades. Sí las hay. Pero quieren ganar mucho y tener semana inglesa. Eso es lo que quiere la gente", comenta Álvaro, quien tiene 35 años y a pesar de su inestable situación económica ha logrado abrir hace poco su propia peluquería.

Mucho menos optimista resulta el discurso de los más desprotegidos: este gira en torno a cierta resignación frente a la precariedad que parece difícilmente superable. El trabajo es narrado primordialmente como un medio (siempre limitado) de supervivencia básica. La escasez, la precariedad y la inestabilidad del empleo son denunciadas como injustas, pero interpretadas como inalterables. La impotencia ante la incertidumbre perpetua desemboca a menudo en actitudes fatalistas o interpretaciones de la precariedad en términos de un destino regido por fuerzas providenciales, fuera del control y entendimiento del sujeto. Ana, de 65 años, quien a pesar de sus continuos esfuerzos de asegurarse el sustento (entre otras maneras reparando y vendiendo electrodomésticos usados) vive al borde de la inseguridad alimenticia, dice:

Duré una rachita muy mala, mala, malísima que no vendíamos nada. Iba yo a la oración [...], le pedía al señor: "Padre mío, tú ves mi necesidad, no te pido riquezas, Señor, no te pido riquezas. Solo una ayudita para comer". Mire, no me lo va a creer: pasaba un rato o... otro día, vendía una estufa o una lavadora o venían por un refrigerador, en un ratito 3000,2000 , ya tenía para comprar la mercancía y comer. Uno no se queda sin nada, Dios no nos deja. 
En una cotidianidad marcada por la inestabilidad y la fragilidad incesantes, la supervivencia es narrada por Ana en términos de milagro: parece no depender ya de sus constantes esfuerzos por mantenerse, sino de una fuerza externa, poderosa, impenetrable.

Finalmente, hay que mencionar también un discurso que presenta el trabajo como un derecho fundamental, quebrantado constantemente por las lógicas del mundo laboral. Desde una posición reflexiva hacia las estructuras existentes, Armado, un universitario de 40 años, comenta:

¿Sabes qué me gustaría? Que los niños que están naciendo, pudiéramos asegurar que tengan trabajos. [...] La pobreza yo creo que es un crimen. No un crimen por parte de la persona, sino un crimen contra la persona.

La precariedad, la inestabilidad y la escasez del trabajo son denunciadas aquí como consecuencia de males estructurales; la delincuencia y la violencia como resultado de las estructuras injustas. Pero, a pesar de la clara crítica a las estructuras, este discurso queda marcado por un cierto desaliento frente a la aparente inalterabilidad de un sistema que, aunque injusto, parece poseer una dinámica difícil de cambiar.

Resumiendo podría decirse que es posible reconocer en lo narrado por los sujetos una cierta resignación (para no decir fatalismo) en relación con el trabajo como una institución que cumple cada vez menos con sus promesas de brindar seguridad; una situación que al mismo tiempo es percibida como improbablemente transformable. Al mundo laboral se le adscriben frecuentemente características de un mundo cuasi natural, cuyas leyes resultan inquebrantables, aunque las posturas de los sujetos frente a él varíen desde críticas de las injusticias hasta los intentos de legitimar el statu quo. Esta aparente no transformabilidad del mundo de trabajo traslada a los hombros del sujeto el peso de asegurar 
su supervivencia. La rigidez de las estructuras del mundo laboral responsabiliza al sujeto de la autotransformación constante, con tal de prevenir o vencer la (siempre posible) precariedad.

\section{La familia como el supuesto 'amortiguador'} de indefensión

La institución de la familia evoca entre los sujetos interpretaciones muy distintas de las que se observan en torno al Estado y el trabajo. Esto llama la atención, porque también esta institución actualmente sufre cambios considerables y se desdibuja frecuentemente como garante de seguridad y de certeza (Ariza y Oliveira, 2009; Enriquez, 2009). No obstante, las expectativas depositadas en la familia se mantienen muy altas: es narrada como un poderoso 'amortiguador' contra la indefensión presente y futura de sus miembros, y como una red de vigilancia que previene riesgos amenazantes de la integridad física. Se espera de ella, incluso, que sea un recinto de valores éticos capaces de revertir el supuesto deterioro moral de la sociedad.

Esta visión de la familia como una supuesta panacea contra las diversas inseguridades e incertidumbres actuales, y la tendencia a depositar en ella el peso de la crisis (en sus diversas facetas) resultan bastante generalizadas en lo narrado por los sujetos; lo cual no significa que esta actitud no carezca de matices y diferencias relacionadas con los condicionamientos sociales de los protagonistas del estudio.

Así, los sujetos que viven en situaciones de precariedad económica (y particularmente los que conjugan esta condición con otras 'vulnerabilidades', tales como la vejez, la enfermedad, la condición de ser madre de hijos pequeños, entre otros) destacan sobre todo el rol de la familia como una red de apoyo mutuo enfocado en la supervivencia inmediata: de los familiares se espera solidaridad y disposición 
de compartir los recursos disponibles (una expectativa no libre de tensiones y frustraciones), como lo expresa Angélica, una joven embarazada de 22 años en situación precaria y madre de dos hijos:

En ese entonces mi cuñado también trabajaba en Aurrerá. $Y$ con el sueldo del Aurrerá para un recién nacido no la libraba. No la libraba. Entonces mis papás ayudaban a veces con leche, a veces con los pañales. Mis papás les echaron mucho la mano. También a uno, pero sí, ahora sí que más a ellos porque, pues, como yo trabajaba, yo se lo dejaba a mi mamá, entonces lo que yo ganaba ya era para... todos tenían que dar chivo porque tenían que pagar comida, tenían que pagar todo [...].

Entre más lejana se vuelve la amenaza de precariedad y vulnerabilidad para los sujetos, más se pueden permitir prescindir de la familia como un garante de la supervivencia. En algunos casos, surgen en este contexto posturas que desafían la exigencia de solidaridad familiar, subrayando la responsabilidad del individuo en la búsqueda de sustento. No faltan sujetos que gracias a su favorable situación económica pueden obviar el rol de la familia como 'amortiguador' de indefensión de carácter económico, aunque varios de ellos declaran buscar en la familia un apoyo emocional en situaciones de crisis.

El clima de inseguridad en la ciudad es creciente y desemboca, entre otras reacciones, en temores respecto al territorio de riesgo que representa el espacio urbano; temores profundizados, además, por la desconfianza generalizada hacia las instituciones relacionadas con la procuración de seguridad ciudadana. En ese contexto, la familia se convierte también en una red de vigilancia que vela por la integridad física de sus miembros. Esta función de la familia es mencionada enfáticamente en las narrativas de padres preocupados por la integridad de sus hijos (aunque no faltan otras parejas vigilante-vigilado). Los padres custodian a sus hijos, les 
imponen límites, los llevan y los recogen, los acompañan constantemente, en persona o a través del teléfono celular. Citlali y Gabriela, madres de hijos adolescentes, resumen así su rol de vigilantes: "Siempre los estoy checando. [...] Tienen el celular los dos y estoy llamándolos. A la escuela yo los llevo" (Citlali); "ellos no salen solos. [...] No les dejo ir a cualquier lugar, a cualquier hora, con cualquier persona" (Gabriela).

En varias narrativas se dibuja claramente la función de la familia como red de vigilancia, objetivada en múltiples prácticas disciplinarias y de control; una tarea que se convierte además frecuentemente en un imperativo moral: un buen padre/una buena madre protege a sus hijos de los riesgos que amenazan su integridad. La preocupación por la seguridad de los hijos es compartida por los sujetos que son padres, independiente de su posición social, aunque los riesgos a los que hacen referencia varían desde el pandillerismo y el narcotráfico hasta los vinculados con los usos de las tecnologías de comunicación.

Queda, finalmente, la visión de la familia como fuente de valores éticos capaces de revertir el supuesto deterioro moral de la sociedad y con él la violencia y la inseguridad imperantes; una expectativa presentada mayormente como incumplida, lo que convierte a la familia en la gran culpable de la presunta crisis moral actual. Esta visión aparece con mayor énfasis y claridad en las narrativas de sujetos con un fuerte apego a una religiosidad de corte tradicional, entendida como un código moral 'incuestionable'; se vincula también frecuentemente con una posición socioeconómica elevada, como es el caso de Salvador, padre de tres hijos adolescentes, quien opina:

Entonces, si un niño ve que sus padres están divorciados, separados, peleados y no hay unión, ¿para qué llega a la casa? Mejor se va con unos amigos de la esquina. $Y$ como no hacen nada y no tienen estudios, dicen: 
Ante las seguridades evanescentes. Riesgo y subjetividades

en la ciudad de Guadalajara

"Oye, ¿cómo obtenemos dinero? Pues a aquel, vamos a sacarle lo que podamos". Y se van con aquel... Entonces la base es los valores, la unión de la familia, todo lo que se tenga que hacer para unir, no para desunir, ¿verdad?

Las críticas de la desintegración de la familia se revelan como actualizaciones de un discurso conservador (promovido, entre otros, por la Iglesia y el Estado), marcado por una nostalgia por la familia tradicional, la cual es presentada como un recinto de rectitud ética (Monsiváis, 2009). Este discurso demuestra una sorprendente permeabilidad y sus huellas son reconocibles en lo narrado por sujetos en diversas posiciones sociales.

En términos generales, es posible argumentar que en la familia se deposita frecuentemente el peso de la crisis en sus diversas facetas, responsabilizándola de la gestión de las tensiones y contradicciones estructurales. Es posible sospechar inclusive una cierta analogía entre la responsabilidad/culpa depositada reiteradamente en la familia (como amortiguador de indefensión, como red de vigilancia y como fuente de valores éticos) y la responsabilidad/culpa que se deposita en el individuo cuando las instituciones (especialmente el Estado y el trabajo) fracasan como fuentes de seguridad y certeza. ${ }^{6}$

\section{La ciudad y los cuerpos: la expansión de lo siniestro}

A tensiones e inquietudes que surgen en relación con la institucionalidad en crisis se suman otras, vinculadas con el paulatino desmoronamiento de la más elemental sensación de seguridad del sujeto-cuerpo, que se vincula con la inseguridad creciente dentro de lo urbano. La ciudad de

6. Aunque esto, por supuesto, podría parecer contradictorio, ya la familia es entendida aquí como una institución social. 
Joanna Jablonska-Bayro

Guadalajara -el espacio concreto, en el que se ve inmersa la corporalidad de los sujetos de esta investigación-se convirtió durante el periodo de la investigación en escenario de violencia e inseguridad crecientes. La vida en la urbe se fue tiñendo gradualmente de la sensación de peligro, riesgo y amenaza.

Sería difícil no asociar este proceso del deterioro de la seguridad en la ciudad con los planteamientos de Anthony Giddens en torno al concepto seguridad ontológica, interpretada por él como el sentimiento de relativa invulnerabilidad que permite dejar en suspenso posibles sucesos capaces de amenazar la integridad del sujeto. Esta barrera protectora "puede ser atravesada, temporal o permanentemente, por acontecimientos que demuestran la realidad de las contingencias desfavorables que implica cualquier riesgo" (Giddens, 1998: 57). Una vez debilitada la seguridad ontológica, el orden de la vida cotidiana, en apariencia estable, se torna frágil y lo conocido revela su rostro siniestro. La vulnerabilidad abandona su latencia y se manifiesta clamorosamente. Se exacerba así la tensión entre la invulnerabilidad postulada y la vulnerabilidad de facto, que atraviesa la relación del sujeto con su propia corporalidad, con el espacio que lo rodea y, finalmente, con las figuras del otro que encarnan las amenazas escondidas dentro de lo urbano que pierde el aura de seguro. Es desde esta tensión entre la invulnerabilidad deseada y la vulnerabilidad vivida que me acerqué analíticamente a los significados y las prácticas de los sujetos entrevistados.

Las referencias a la ciudad como espacio amenazado y amenazante abundan en las narrativas analizadas. Los sujetos relatan la sensación de la paulatina pérdida de la ciudad en cuanto un espacio de seguridad, confianza y libertad: disminuye del "espacio tópico" (propio y conocido) y se ensancha simultáneamente el "espacio heterotópico" que "alude al territorio de los 'otros' y que representa esa 
geografía atemorizante en la que se asume que 'suceden cosas" (Reguillo, 2003: 4). La experiencia de habitar y transitar por la ciudad significa para varios sujetos entrevistados el desafío de encuentros con este otro latentemente amenazante, capaz de convertir lo conocido y lo cotidiano en lo siniestro.

Especialmente inquietantes resultan en este contexto las figuras del otro asociadas con una potencial agresión premeditada: los "depredadores" urbanos acechando a sus presas. Entre ellos, los asaltantes son mencionados con gran frecuencia, seguidos de extorsionadores y secuestradores. Los sujetos entrevistados hacen referencia a la potencial omnipresencia y la capacidad de camuflaje de los "depredadores", las supuestas ventajas que tienen sobre sus presas (astucia, perspicacia, acceso a la información), su "creatividad" en cuanto a cada vez más sofisticadas maneras de delinquir, la misteriosa capacidad de inducir y profundizar la indefensión de sus víctimas, la crueldad y violencia que conllevan el riesgo de agresión física y muerte.

Pero hay una figura que provoca una inquietud aún mayor: los narcotraficantes, asociados por los sujetos con la violencia desbordada. Los narcos son narrados como despiadados y sanguinarios, relacionados con prácticas tales como atentados (bombas, "granadazos"), balaceras, bloqueos de avenidas con vehículos incendiados, extorsiones, secuestros y ejecuciones. La sensación de la potencial omnipresencia del peligro se condensa en el temor de estar en un lugar incorrecto en un momento incorrecto y convertirse así en víctima colateral, como lo expresa Gustavo de 18 años, hijo de una pudiente familia tapatía:

Sentirte completamente seguro [en la ciudad]... no, no creo que lleguemos a ese punto, porque siempre hay un riesgo. Que sales en el coche... porque a fuerzas vas a lugares... vengo a la escuela... siempre hay un riesgo que te toque allí un... pues... estar en el lugar incorrecto. 
Joanna Jablonska-Bayro

[...] En ese momento que... hay una persecución allí y que te lleguen a impactar allí por cualquier cosa y, pues, tú sales perjudicado.

El miedo de encontrarse por accidente en un fuego cruzado representa la quintaesencia de la sensación de riesgo ubicuo y difuso que ya no puede ser relegado a esferas circunscritas y lejanas. En este sentido, la figura del narco simboliza (de manera especialmente elocuente e inquietante) el gradual y cada vez más profundo desmoronamiento de los límites acostumbrados entre lo seguro y lo inseguro, y con él, la tensión cada vez más pronunciada entre la invulnerabilidad deseada y la vulnerabilidad de facto, en la que subyace, en última instancia, la preocupación por la integridad del cuerpo.

Son abundantes y diversos los significados y las prácticas en torno al cuerpo expuesto a riesgos escondidos en el espacio de la ciudad; les subyace la concepción del sujeto-cuerpo vulnerable, que, al abandonar el territorio seguro del refugio (la casa, para la mayoría de los sujetos), se adentra en el espacio potencialmente peligroso de la ciudad, en el que resulta preciso mantenerse en alerta constante con tal de salvaguardarse. Autocontrol y disciplina resultan aquí cruciales. "Ya no me expongo tanto - confiesa Salvador, habitante de un fraccionamiento cerrado, convencido de que la seguridad de cada quien depende de su comportamiento- trato de cuidar los límites. Cuidar los horarios. Cuidar las situaciones a donde voy". También Lorena, una joven que vive en un barrio popular, declara cuidarse de no transgredir los límites de tiempos y espacios 'prohibidos': "yo nunca frecuento ese tipo de lugares, aunque me queden muy cercanos". ${ }^{7}$

7. Resulta importante añadir que, ante los riesgos de lo urbano, los sujetos entrevistados conjugan frecuentemente la "racionalidad" de las prácticas de autocontrol con la búsqueda de protección sobrenatural. La lista de protectores sobrenaturales, encabezada por Dios, incluye también a diversos santos, ángeles, seres de luz y de sanación, entre otros. Lorena, quien respeta meticulosamente el código de autocontrol al recorrer la ciudad, declara también confiar en la protección angelical. 
Ante las seguridades evanescentes. Riesgo y subjetividades

en la ciudad de Guadalajara

Los comentarios citados, referidos a las prácticas de autocontrol y disciplina, permiten vislumbrar al mismo tiempo los constantes esfuerzos de los sujetos por diferenciar entre los espacios tópicos y heterotópicos. Cada uno de ellos traza en su narrativa lo que podríamos quizá denominar un mapa de riesgos; una guía (siempre contingente) para orientarse en lo urbano que, como un caleidoscopio, revela cada vez nuevas amenazas. La ciudad narrada y practicada por los sujetos, independiente de su posición social o espacio habitado, aparece marcada por la (ya mencionada) dicotomía entre el espacio propio, seguro y conocido, y el ajeno, plagado de peligros; aunque la diferenciación y el contraste entre ambos no siempre poseen la misma intensidad u 'obviedad'. El riesgo que marca el espacio de la ciudad parece ubicarse siempre en las afueras de lo propio, vehementemente defendido; el espacio tópico, por su parte, es presentado frecuentemente como un potente 'refugio antiamenazas'.

Esta polarización entre el adentro (seguridad) y el afuera (riesgo) es especialmente visible en las narrativas de los habitantes de los fraccionamientos cerrados, cada vez más comunes dentro de la ciudad (Cabrales y Canosa, 2001). La percepción de la ciudad 'abierta' como un espacio amenazante es observable, entre otros, en la narrativa de Lidiana, madre de cuatro hijos y habitante de uno de los cotos más lujosos de la ciudad:

Yo... por lo regular mis salidas... ¿Qué son? Ir la escuela, recoger a mis hijos y regresarme. En la tarde, como estas escuelas que tienen la opción de que tus hijos tienen las actividades después de salir del horario, para mí ha sido maravilloso. ¿Por qué? Porque yo ya no tengo que salir. Si se me ofrece algo, no sé, que a mis hijos les piden lo que quieras y gustes, mi esposo (ese acuerdo tenemos)... le hablo y de regreso a casa llega a la papelería, a lo que sea necesario, pues. Pero ya casi no salgo, casi no salgo.

Sociedad $\&$ No. 60 
Joanna Jablonska-Bayro

Mantenerse adentro lo más posible, limitar las salidas, recurrir a la burbuja protectora del automóvil, en caso de traslado, asegurar los agujeros y fisuras por las que los riesgos, siempre externos, podrían invadir la zona de seguridad (cambiar el número de teléfono en caso de llamadas de extorsión, por ejemplo) son prácticas presentadas por algunos de los sujetos, no sin cierto orgullo, como ejemplo de su manejo exitoso de la situación de inseguridad. Entre más difusas y omnipresentes se vuelven las amenazas de lo urbano, más desesperados devienen los esfuerzos por resguardar lo que queda de la ciudad habitable. El lograr expulsar el riesgo al espacio del otro se convierte en la promesa de poder resguardar la frágil seguridad de uno mismo (aunque sea temporalmente); una promesa sin duda seductora, ya que el 'refugio' representa para los sujetos un recinto de relativa invulnerabilidad: perderlo significaría enfrentarse a una vulnerabilidad total e irrevocable.

En términos generales, es posible notar que en la ciudad marcada por un riesgo ubicuo, cercano y cada vez menos pronosticable la tensión entre la vulnerabilidad vivida y la invulnerabilidad deseada tiende a encontrar su desenlace en esfuerzos por deslindar lo seguro de la amenaza, aunque a veces solo temporalmente o de manera parcial. Aislar los riesgos parece ser la clave: otorgarles límites o equiparse uno mismo de límites no traspasables. De ahí la abundancia de significados y prácticas en torno al acorazamiento del cuerpo, la definición del otro amenazante, las distinciones entre las zonas de riesgo y las zonas seguras, la defensa de los refugios; esfuerzos por alejar las amenazas que, ante la institucionalidad en crisis y la sustitución de la solidaridad por la responsabilidad individual, se convierten frecuentemente en la solitaria tarea del sujeto-cuerpo. 


\section{Lo común 'inmunizante’}

Los hallazgos presentados aquí permiten vislumbrar la individualización como un proceso importante y multifacético que condiciona de diferentes maneras las subjetividades que se configuran en relación con los riesgos actuales. El debilitamiento del trabajo y del Estado como fuentes de seguridad, y la consiguiente colocación de la responsabilidad -cada vez mayor- en los hombros del sujeto; la familia imaginada a imagen y semejanza de un sujeto todoresponsable; lo urbano marcado por la expansión de lo siniestro que fragmenta y divide asignando a cada quien su espacio celosamente defendido y protegido... En las cuestiones abordadas subyace la concepción de un sujeto individualizado, aunque se exprese de maneras diversas.

En contraste, las concepciones de lo común, lejos de saltar a la vista, resultan difícilmente rastreables en lo narrado por los sujetos. En cierto sentido podría decirse que lo común brilla aquí por su ausencia. Una mirada más atenta revela, no obstante, que esto no es del todo cierto. Aunque son escasas, las menciones de lo común presentes en las narrativas atestiguan que los sujetos no descartan la idea de una comunidad solidaria como respuesta ante el riesgo. Sin embargo, esta comunidad añorada aparece atravesada frecuentemente por una paradoja: las menciones de lo común presentes en las narrativas revelan que, lejos de ser concebido como una diversidad compartida, lo común es ideado a imagen y semejanza de un individuo en busca de protección: un estar juntos en el que subyace, en última instancia, la preocupación por la protección del cuerpo vulnerable y amenazado. Lo común, así concebido, se convierte paradójicamente en una expresión más de la búsqueda de la defensa de lo propio.

El carácter paradójico de lo común concebido de esta manera es abordado lúcidamente por Roberto Esposito 
Joanna Jablonska-Bayro

(2003, 2005), quien opone esta concepción específica de lo común (profundamente moderna, según el filósofo) a la idea de la communitas, que se constituye justamente por oposición a lo propio, a través del deber y de la deuda con los demás. La communitas de Esposito es intrínsecamente ambivalente: esconde tanto beneficios como amenazas, entre ellas también la amenaza de muerte. En respuesta a este aspecto entrópico y amenazante de la communitas, se constituye, según el autor, lo común moderno que aísla y protege a los individuos, liberándolos al mismo tiempo de la deuda que los vincula mutuamente. Por eso también, el contrapunto semántico más incisivo de la communitas es conformado, según Esposito, por la categoría de immunitas. El autor sugiere que esta categoría podría entenderse como clave explicativa de todo el paradigma moderno: la modernidad se afirma 'inmunizando' al sujeto, o, en otras parabras, separándose de un orden al que subyace el concepto ambivalente de munus: don y obligación, beneficio y prestación, conjunción y amenaza.

Esposito propone vincular el desarrollo y la intensificación de las dinámicas 'inmunitarias' con el surgimiento del Estado moderno y sus instituciones que, a cambio de obediencia, protegen al ciudadano de la communitas ambivalente. Sin embargo, es posible argumentar que estas instituciones están debilitándose actualmente como garantes de la immunitas, y la tarea de buscar certidumbre y seguridad cae, cada vez más, en los hombros del sujeto (como lo demuestran, entre otros, los hallazgos de esta investigación). En esta situación, la búsqueda de la immunitas se privatiza y se fragmenta, objetivándose, entre otros, en la multiplicación de "comunidades" que prometen a los que gozan del privilegio de ser incluidos en ellas la protección contra las amenazas que asechan en las afueras.

En cuanto a las narrativas analizadas, la tendencia que emana de ellas parece ser la búsqueda de lo común dentro de 
vínculos primarios: la familia es narrada por muchos como su principal experiencia de estar juntos. Como la casa, que se convierte en el refugio por excelencia dentro del espacio de la ciudad, la familia parece cumplir con la misma función en el espacio social. El vecindario, por otro lado, es narrado a menudo como una "comunidad" difícil y profundamente ambivalente que no carece de una cierta solidaridad, pero a la vez es percibida como fuente de posibles amenazas. Incluso los fraccionamientos cerrados, que a primera vista podrían dar la impresión de ser las objetivaciones más acabadas de la idea de una comunidad de semejanzas que protege a sus miembros, se revelan ambivalentes: sus habitantes los elogian como espacios tranquilos y protegidos, pero no mencionan a sus vecinos o los mencionan en términos mayormente negativos. La convivencia vecinal parece no constituir un elemento clave en su experiencia de habitar el fraccionamiento.

Por otro lado, hablando de lo común en su modalidad 'inmunizante' hay que mencionar ciertas colectividades religiosas o cuasi religiosas con las que se identifican algunos de los sujetos entrevistados. Resulta interesante observar que las comunidades de sentido (Berger y Luckman, 1997) a las que eligen pertenecer les ofrecen no solamente la certidumbre compartida, sino también una sensación de seguridad, fruto de su apego a las normas de la comunidad en cuestión.

En este sentido, un ejemplo especialmente sugerente se observa en la narrativa de Elías y Ana, miembros de la Iglesia de La Luz del Mundo, una congregación religiosa pentecostal relativamente cerrada y con una estructura jerárquica y una normatividad exacerbada (De la Torre, 2000). El líder de la Iglesia, el único mediador entre lo profano y lo sagrado, une características del buen pastor con las del padre castigador. El privilegio de gozar de su sombra protectora tiene un precio irrevocable: la obediencia a las 
prescripciones de la doctrina. Aquí, las certezas carecen de ambigüedad y garantizan, además, la seguridad, siempre y cuando los miembros de la comunidad se mantengan dentro de los límites de lo permitido. Es afuera donde pululan la depravación y el pecado, consecuencia de la ignorancia o de la trasgresión deliberada. La comunidad de los fieles, por lo contrario, es un reino de pureza, bendición y amparo. De ahí que los sujetos se narren así mismos como inmunes frente a posibles riesgos presentados como resultado de la confusión moral:

Si todos los malvivientes no hubiera, había la gente más tranquila, más pacífica, no había tantos muertos, yo simplemente veo gente que están, dizque... el otro día los que estaban cenando en la noche en un restauran, ¡nooo!, los ametrallaron, los mataron. ¡Caray! Pues ¡qué, pues! Gente inocente que no debía. Borrachos allí andan, en las carreteras. Nada menos ahora, ¡cuántos carros chocaron! Se murieron diez. Por la imprudencia de esos... de los borrachos. $Y$ eso es lo que estamos enseñados: a no tomar, a no ser malvivientes, a no ser rateros, a no maltratar de las personas que no tienen culpa de nada, todo eso es lo que tratamos y lo que nos han enseñado. $Y$ nosotros lo tratamos de poner por obra. Es lo que le digo. Entonces todas estas cosas, mientras Dios no quiera, a nosotros no llega. Y, sí, no temas, el mal a ti no vendrá, pero ¿cuándo?, cuando tú hagas el bien, cuando tú lo que Dios manda, lo que Dios quiere... Entonces allí es donde está el secreto de uno.

Esta comunidad de certeza-con-seguridad, narrada por Elías y Ana, ofrece, sin duda, un ejemplo especialmente elocuente del poder protector de una comunidad de sentido. Sin embargo, no constituye una excepción: en la narrativa de Salvador (quien se declara católico practicante) es posible reconocer una visión de la religión como garantía de certeza y seguridad que resulta similar a la anterior en muchos aspectos. El sujeto expresa reiteradamente su profunda convicción en que existe una ética universal, eterna e incues- 
tionable que permite a sus conocedores tomar decisiones siempre correctas. Comentando sobre un hipotético contacto con narcotraficantes (quienes en su narrativa encarnan el pecado), Salvador afirma:

Yo veo lo malo, lo detecto y lo observo, pero no me gusta rascarle mucho. Porque yo sé la solución. Si las personas no quieren hacerlo, es su responsabilidad. [...] Me retiraría un poco. Mejor. Creo que es lo más sano. El proverbio dice..., perdón que esté insistiendo, pero allí dice, en esas 15 hojitas [el Libro de los Proverbios] dice todo. Dice ahí: "Cuando veas una ocasión que no es correcta, dale la vuelta". Si tú ves que vas a pasar por un punto donde hay riesgo o peligro, dale la vuelta, y no te va mal. Eso es indiscutible. Es este..., es lo que Jesucristo dijo, viene por añadidura. Si tú haces cosas buenas, lo demás viene por añadidura. [...] Pero si empiezas coquetearle con que el dinero y etc., ahí empiezan los riesgos.

El conocimiento de las reglas divinas provee a la comunidad de los fieles no solamente de certezas de carácter moral, sino parece brindarles también un recetario de reglas prácticas de seguridad cotidiana. Gracias a su ética clara y patente, son capaces de evitar un posible "contagio" con el mal y así evitar riesgos.

Finalmente, hablando del poder protector adscrito por los sujetos a sus creencias vinculadas con la pertenencia a ciertas comunidades de sentido, vale la pena mencionar la narrativa de Gabriela, adepta de la corriente místicoesotérico-espiritual y maestra de yoga. Su "comunidad" (conformada por sus alumnos, amigos y pareja) se caracteriza por el acceso a una serie de verdades trascendentales que permiten a los iniciados romper con los vicios del mundo que los rodea, el cual está marcado por el miedo, la represión, el desequilibrio, la agresividad, la tristeza y la falta de amor. De manera que lograr un nuevo nivel de consciencia les brinda liberación, purificación, equilibrio, paz y armonía. 
Los peligros y riesgos de la cotidianidad son interpretados aquí ya no en clave de pecado, sino como desequilibrio y trastorno de los flujos de la energía positiva. En respuesta, los iniciados desarrollan prácticas que les permiten 'acorazarse' contra las amenazas:

Hay cosas que tú atraes porque vibras en eso y te tienen que pasar [...]. Entonces lo que pasa en estos cursos es que vas desbloqueando esos registros, los vas abriendo, porque, era lo que yo te decía, en lo que tú vibras, es lo que tú atraes. Si todo el tiempo estás teniendo miedo, pues algo te va a pasar, porque lo estás jalando, ¿no? Entonces abres estos registros y empieza a fluir mejor la... esa energía hacia ti.

Aquí, nuevamente, las creencias brindan no solamente un conjunto de certezas que permiten una interpretación de la realidad marcada por el riesgo, sino prometen también la seguridad que en este caso resulta ser fruto de una nueva consciencia.

Las comunidades de sentido a las que hacen referencia algunos de los sujetos parecen edificaciones cuidadosamente construidas para brindar a los que gozan del privilegio de resguardarse dentro de sus muros una visión del mundo tan coherente que parecen no existir en él fisuras ni grietas por las que podrían penetrar dudas o peligros. No obstante, esta pretensión de crear una comunidad de certeza-conseguridad, "suave y aterciopelada por dentro y espinosa y pinchuda por fuera", cuya armonía interna "reluce y centellea contra el fondo de la oscura y enmarañada jungla que empieza del otro lado del portal" (Bauman, 2003:183) está atravesada por la ya mencionada paradoja de que la comunidad, presentada como un antídoto contra las precariedades del sujeto individualizado, se concibe como una "subjetividad más vasta" o "unidad de unidades" (Esposito, 2003: 25); una concepción de lo común que encuentra en el cuerpo aislado su más acabada metáfora: lo común como 
fusión de cuerpos, que tiene como resultado un cuerpo más grande, más protegido, inmune; un nosotros excluyente en el que el sujeto-cuerpo se protege de los riesgos de la otredad y espera inmunizarse contra lo que lo altera, lo transforma, lo corrompe; lo común que se revela como una expresión más de la individuación.

\section{Reflexiones finales}

En este artículo se presentaron algunos de los hallazgos del estudio que partió de la inquietud sobre del riesgo como configurador de subjetividades, y que giró en torno a la pregunta por las subjetividades que se configuran en relación con los riesgos contemporáneos. A lo largo del análisis fue posible observar las posturas de los sujetos frente al riesgo en sus diversas facetas; también, las tensiones que ellos enfrentan en el contexto de una realidad marcada por la creciente inseguridad e incertidumbre.

En términos generales, es posible argumentar que el estudio permite constatar el poder individualizador y fragmentador del riesgo. Los riesgos enfrentados por las y los sujetos en el contexto de la individuación en progreso aunados a la crisis de lo institucional y al debilitamiento de lo común parecen fomentar y profundizar adicionalmente la individuación. Cuando el acceso al empleo depende de los solitarios esfuerzos de cada quien por perfeccionar su adecuación, cuando no se confía en el vecino y se confía solamente en la familia y en los amigos más cercanos, cuando los lugares públicos se convierten para algunos en sinónimo del peligro y la casa en un refugio anti-amenazas, resulta difícil vislumbrar en el riesgo la fuente de una nueva solidaridad, como proponen algunos autores (Beck, 2008; Cavarero, 2009; Morin, 2004) que sea interpretado.

Además, los hallazgos del estudio permiten explicar el riesgo como un potente dispositivo de control. En un 
Joanna Jablonska-Bayro

ambiente marcado por peligros que se antojan omnipresentes, cada vez más cercanos y difícilmente predecibles, el sujeto se encuentra frente al imperativo de valerse por sí mismo: es responsabilizado de su éxito o fracaso ante el riesgo. Conforme se desdibujan las instituciones como fuentes de seguridad y protección, la tarea de resguardarse cae en los hombros del sujeto. De él depende lograr mantener su empleo por más que los pocos meses garantizados en su contrato temporal; de él depende saber evitar la incriminación de un policía corrupto; poder evadir el ataque de los 'depredadores' urbanos; elegir el santo patrón correcto para la protección, o bien la modalidad apropiada de superación personal para autotransformarse exitosamente.

De esta manera, la agencia del sujeto parece 'atrapada' en la febril búsqueda del aseguramiento de la supervivencia y el sujeto se revela replegado sobre sí mismo en los perpetuos esfuerzos por autoprotegerse. Paradójicamente, en el contexto de riesgo, la responsabilidad colocada en el sujeto, que en apariencia lo empodera, se revela como una poderosa modalidad de control social, ya no impuesto por las instituciones disciplinarias (Foucault, 1979), sino colocado por el sujeto mismo (y por ello, quizá, especialmente efectivo).

La visión del sujeto que surge a partir del análisis es la de un sujeto que se sabe vulnerable y al mismo tiempo obligado a valerse por sí mismo, recogido en sí mismo, en los intentos de no exponerse a la catástrofe siempre posible. Este es, por supuesto, un diagnóstico poco alentador. Sin embargo, al dilucidar ciertos aspectos de la relación entre el riesgo y las subjetividades, este diagnóstico, referido a un aqui y ahora concreto pero inmerso al mismo tiempo en el amplio contexto de lógicas y dinámicas características de lo contemporáneo, permite vislumbrar una cuestión mucho más abarcadora, a saber, nuestra concepción del sujeto y su relación con lo común. 
Ante las seguridades evanescentes. Riesgo y subjetividades

en la ciudad de Guadalajara

La idea del sujeto autosuficiente, hermético, acorazado, separado del exterior, que defiende su totalidad negando su propia fragilidad y dependencia, se esconde en lo más profundo de las dinámicas éticas, políticas, económicas y culturales de la modernidad. Mi investigación podría entenderse como una invitación al cuestionamiento de esta concepción moderna del sujeto que se oculta en la promesa salvífica colocada en el reino de lo individual. Esta no es, por supuesto, una propuesta original ni excepcional. Varios autores contemporáneos destacan la importancia de cuestionar y de desestabilizar esta concepción del sujeto, revelando sus paradojas, sus peligros, su carácter ilusorio (Esposito, 2005; Cavarero, 2009; Butler, 2006). Este estudio constituye un punto de partida para la reflexión sobre las posibilidades de concebir el sujeto y su relación con lo común de maneras diferentes y, por lo tanto, sobre las posibilidades de la apertura de nuevas formas, más plurales e incluyentes, de vínculos, reciprocidades y solidaridad.

Fecha de recepción: 21 de marzo de 2014

Fecha de aceptación: 22 de mayo de 2014

Ariza, Marina y Orlandina de Oliveira, 200I, "Familias en transición y marcos conceptuales en redefinición”, Papeles de Población, no. 28, pp. 9-39.

Bauman, Zygmunt, 2005, Vidas desperdiciadas. La modernidad y sus parias, Paidós, Barcelona.

Beck, Ulrich, 2008, La sociedad del riesgo mundial. En busca de una seguridad perdida. Paidós, Barcelona.

Berger, Peter y Thomas Luckmann, 1997, Modernidad, pluralismo y crisis de sentido. La orientación del hombre moderno, Paidós, Barcelona.

Butler, Judith, 2006, Vida precaria. El poder del duelo y la violencia, Paidós, Barcelona.

Bibliografía

Sociedad $\&$ No. 60 
Joanna Jablonska-Bayro

Bibliografía

Cabrales Barajas, Luis Felipe y Elia Canosa Zamora, 200I, "Segregación residencial y fragmentación urbana: los fraccionamientos cerrados en Guadalajara”, Espiral. Estudios sobre Estado y sociedad, vol.7, núm. 20, pp. 223-253.

Cavarero, Adriana, 2009, Horrorismo. Nombrando la violencia contemporánea, Anthropos, Barcelona.

De la Torre, Renée, 2000, Los hijos de la luz. Discurso, identidad y poder en La Luz del Mundo, ITESO/CIESAS/ Universidad de Guadalajara, Guadalajara.

Enriquez Rosas, Rocío, 2009, "Configuraciones/reconfiguraciones familiares y violencia doméstica/social en la ZMG”, en Guadalupe Rodriguez Gómez (coord.), Diagnóstico sobre la realidad social, económica y cultural de los entornos locales para el diseño de intervenciones en materia de prevención y erradicación de la violencia en la región Centro: el caso de la zona metropolitana de Guadalajara, Jalisco, en línea: http://www.conavim.gob.mx/work/ models/CONAVIM/Resource/pdf/GUADALAJARA.pdf

Esposito, Roberto, 2003, Communitas. Origen y destino de la comunidad, Amorrortu, Buenos Aires. , 2005, Immunitas. Protección y negación de la vida, Amorrortu, Buenos Aires.

Foucault, Michel, 1976, Vigilar y castigar, Siglo XXI, México. Giddens, Anthony, 1998, Modernidad e identidad del yo. El yo y la sociedad en la época con-temporánea, Península, Barcelona.

Monsiváis Carlos, 2009, “México en 2009: la crisis, el narcotráfico, la derecha medieval, el retorno del PRI feudal, la nación globalizada", Nueva Sociedad, núm. 220, pp.42-59.

Morin, Edgar, 2004, "En el corazón de la crisis planetaria”, en Jean Baudrillard y Edgar Morin, La violencia del mundo, Paidós, Barcelona. 
Ante las seguridades evanescentes. Riesgo y subjetividades en la ciudad de Guadalajara

Reguillo, Rossana, 2003, “Utopías urbanas. La disputa por Bibliografía la ciudad posible”, Revista Ciudades, octubre-diciembre, pp.3-8.

, 2007, "Formas de poder. Narrativas y poderes diferenciales en el paisaje noeliberal", en Alejandro Grimson (comp.), Cultura y neoliberalismo, CLACSO, Buenos Aires, Pp.91-I 10

Vara, M. J., 2006, "Precarización de la existencia y huelga de cuidados”, en J. M. Vara (coord.), Estudios sobre género y economía, AKAL, Madrid.

Williams, Raymond, 2000, Marxismo y literatura, Península, Barcelona. 